\title{
Controlando el regimiento. La nobleza de Talavera de la Reina y sus métodos de intervención política en el concejo en la Baja Edad Media
}

\author{
Controlling the councilmen. The nobility of Talavera de la Reina \\ and their methods of political intervention in the council in the \\ Late Middle Ages
}

\author{
Alicia Lozano Castellanos \\ Universidad de Castilla-La Mancha \\ alicia.lozano@alu.uclm.es
}

Recibido: 20/11/2014

Aceptado: 17/02/2015

\begin{abstract}
RESUMEN
¿Cómo mantener el poder político en un concejo - Talavera de la Reina- en el que los oficios regimentales no habían sido patrimonializados? Esta cuestión, poco frecuente en las ciudades y villas castellanas bajomedievales, fue, desde la instauración del regimiento a finales del siglo XIV, uno de los principales asuntos del ámbito político a los que hubo de hacer frente la élite de poder talaverana compuesta, principalmente, por el estrato nobiliario de la villa. El objetivo de las presentes páginas es analizar la respuesta de este sector social ante la problemática que se les planteaba al no poder transmitir su cargo regimental a sus herederos. En este sentido, la estrategia seguida por la nobleza talaverana giró en torno a dos ejes, principalmente: eliminar la competencia que suponía la élite pechera en el control político del concejo y asegurar únicamente el acceso al regimiento de los miembros del estrato nobiliario. Para ello, desarrollaron un procedimiento que les garantizaba el control de los aspirantes a la regiduría vacante basado, fundamentalmente, en la votación y elección de los candidatos entre los integrantes de los linajes nobiliarios del concejo, siempre que no pertenecieran a la familia del oficial fallecido. Según este sistema, los miembros de los linajes regimentales mejor posicionados quedaban en una suerte de lista de espera, aguardando a que les llegase su turno para poder competir por el acceso a una regiduría. Como consecuencia de ello, para recabar los apoyos necesarios en este proceso, se desarrolló un complejo entramado de relaciones y alianzas sociopolíticas entre las familias del grupo dominante, cuya línea de actuación estuvo dirigida a asentar su poder político en el concejo.
\end{abstract}

Palabras clave: Castilla, Baja Edad Media, Talavera de la Reina, Regimiento, Nobleza.

\begin{abstract}
How can political power be controlled in a village -Talavera de la Reina- where the most important municipal public offices -the regidurías- are not subject to transfer from fathers to sons? This was an unusual problem in most Castilian towns by the end of the Middle Ages, but in Talavera it constituted one of the main political issues for the town's power elite since the introduction of the regimiento at the end of the 14th Century. The aim of this paper is to analyse the solution given to this problem by the dominant group, principally composed of the nobility of the village. In this sense, the strategy followed
\end{abstract}


by the nobility of Talavera de la Reina was focused on two goals: to drive out the common elite as competitors for power and to ensure the access of the members of the nobility to the town council government. This was the reason why they developed a process that guaranteed them the control over the lists of candidates to replace vacant positions inside the regimiento. This system was based on the election of the applicants among the members of the noble lineages of the village, but the aspirants could not be a relative of the deceased officers. According to this process, the best positioned members of the families that composed the regimiento were on a kind of waiting list, expecting their turn to gain access to the highest office in town: a regiduría. The main consequence of this practice was the development of a complex network of social and political relationships and alliances between the families of the dominant group whose main goal was to achieve the control of the government of the village.

Key words: Castile, Late Middle Ages, Talavera de la Reina, Regimiento, Nobility.

Sumario: 1. Introducción. 2. La institución regimental en Talavera de la Reina: mecanismos de acceso, control y perpetuación en el cargo. 3. La participación de la élite pechera en el gobierno urbano. 4. El proceso de acaparamiento de los oficios regimentales por la nobleza talaverana. Los mecanismos de control de acceso al cargo. 5. Injerencias exteriores y ruptura del proceso de elección. 6. Conclusiones.

\section{INTRODUCCIÓN}

En los últimos siglos medievales la ciudad se convierte en centro de los intereses socio-políticos e incluso económicos de la nobleza, que ha ido accediendo a los más importantes cargos concejiles, al tiempo que levantaba en suelo urbano espléndidas residencias y torres, símbolo de su poder ${ }^{1}$.

Como afirma Quintanilla Raso, en los siglos bajomedievales la relación de la nobleza con las ciudades y villas castellanas se intensificó, especialmente en los ámbitos político y económico. Finalizado el período de conquista, el estrato nobiliario giró sus intereses hacia el ámbito urbano, centrándose en el gobierno y control de los recursos concejiles. El culmen de este proceso se obtuvo con su exitosa monopolización de los cargos regimentales, oficios que lograron convertir en vitalicios y, en la mayoría de los casos, hereditarios.

Como bien es sabido, desde los años finales del reinado de Alfonso XI y durante prácticamente la segunda mitad del siglo XIV, se fueron instaurando los regimientos, o concejos cerrados, en las ciudades y villas castellanas, como fruto de una serie de factores principalmente de índole socio-económica. La mayoría de autores que han estudiado la introducción de los regimientos, coinciden en señalar como una de las principales causas de la instauración del mismo la serie de cambios sociopolíticos que tuvieron lugar entre los siglos XIII y XIV cuando, tras la detención de la conquista, los caballeros villanos reorientaron sus intereses hacia el ámbito urbano, con el objeto de garantizar su dominio sobre este espacio tras el declive de sus actividades

\footnotetext{
1 Quintanilla Raso, "El dominio de las ciudades por la nobleza”, p. 109.
} 
militares ${ }^{2}$. Por lo tanto, la institucionalización de estas estructuras de poder no suponía sino la sanción del modelo sociopolítico existente en cada municipio ${ }^{3}$.

El estudio de la introducción, formación, composición y control de los mecanismos de acceso y funcionamiento de los regimientos castellanos bajomedievales ha sido, y es, un tema que ha suscitado el interés de numerosos medievalistas. Gracias a las diversas monografías sobre concejos medievales en las que, generalmente, se abordaba esta cuestión como un capítulo en dichos trabajos, la historiografía española ha obtenido una imagen muy completa de la realidad de las instituciones regimentales bajomedievales castellanas ${ }^{4}$.

Desde la constitución de los concejos cerrados o regimientos a lo largo del siglo XIV y primeras décadas del Cuatrocientos, la clase dominante urbana, compuesta principalmente por los estratos nobiliarios municipales y los caballeros villanos, inició un proceso de monopolización y control de acceso a los puestos de gobierno concejil, conscientes de los beneficios personales que les podía reportar la gestión del poder político urbano.

Siguiendo esta línea, el objetivo principal de estas páginas es analizar la composición social del regimiento de Talavera de la Reina a finales del Medievo y los mecanismos de acceso al cargo que fueron desarrollados por los oficiales concejiles dado que, como desarrollaremos a continuación, y a diferencia de lo que se ha documentado para otros concejos castellanos, el cargo regimental en Talavera de la Reina no fue patrimonializado por los linajes que ocupaban dichos oficios. En nuestro caso, hemos desarrollado tres campos de observación, centrándonos especialmente en los

2 Cerdá Ruiz-Funes, "Hombres buenos, jurados y regidores", p. 180. RucQuor, "Valladolid, del concejo a la Comunidad”, II, p. 751. Asenjo GonzÁlez, Segovia: la ciudad y su tierra, p. 414. Monsalvo AnTón, El sistema político concejil, p. 144. Asenjo GonZÁlez, Espacio y sociedad, pp. 505-506. Del VAL VALDIVIESO, "The urban oligarchy's affairs". JARA FuENTE, "Estructuras formales de poder", p. 229. Collantes DE TERÁN SÁnchez, "Las ciudades de Andalucía", p. 237.

3 JARA FuENTE, "Estructuras formales de poder", p. 227.

${ }^{4}$ El listado de títulos de monografías sobre concejos castellanos bajomedievales publicadas desde finales de la década de 1970 es muy extenso, por lo que, por cuestiones de espacio, remitimos a cuatro trabajos en los que se realiza un buen balance historiográfico sobre este tema. Monsalvo AnTón, "La sociedad política en los concejos castellanos", pp. 357-413; Martín Cea y Bonachía Hernando, "Oligarquías y poderes concejiles", pp. 17-40; AsENJo GonZÁLEZ, "Las ciudades medievales castellanas”, pp. 415-453; JARA FuENTE, "Estructuras formales de poder", pp. 225-241. Monsalvo Antón, en el trabajo mencionado, hace un intenso recorrido sobre la introducción del sistema regimental en los concejos castellanos de ambas mesetas, abordando una amplia cronología, desde finales del siglo XIII hasta el siglo XV. Por su parte, los textos de Martín Cea y Bonachía Hernando y Asenjo González, abordan la cuestión del sistema de gobierno local desde una perspectiva social. Martín Cea y Bonachía Hernando tratan la relación de la evolución sociopolítica de los concejos en referencia al sistema feudal, y la influencia de éste en el nuevo modelo. En relación a ello, analizan con mayor profundidad la elitización del sistema urbano de poder, los esfuerzos de los grupos dominantes por hacerse con el completo control de los mecanismos de gobierno y, finalmente, el papel jugado por el común, como freno a las aspiraciones de este colectivo. Por su parte, Asenjo González centra su estudio en la dinámica de relaciones de poder, con un campo de análisis interesado, principalmente, en la creación y desarrollo de los linajes urbanos, desde sus orígenes hasta su definitivo asentamiento en las ciudades y villas y su establecimiento como élite dominante concejil. Finalmente, Jara Fuente aborda el estudio de la composición de los concejos desde una óptica inter e intraurbana. En su trabajo, se tratan cuestiones como la composición y mecanismos de funcionamiento de la élite dominante en diferentes concejos, y la adaptación de los mismos al nuevo sistema de gobierno urbano generalizado en Castilla desde mediados del siglo XIV. 
mecanismos de acceso y control de los que se sirvió la nobleza talaverana para intervenir en esta institución.

En primer lugar, estudiaremos el modelo regimental desarrollado en un estadio inicial, cuya principal característica era la composición del cabildo por los linajes de la élite del común mejor posicionados en el entramado social talaverano y por algunos de los linajes nobiliarios que habitaban en Talavera de la Reina. El segundo punto de análisis trata sobre los mecanismos empleados por las familias de la clase dominante pertenecientes, generalmente, al estrato privilegiado, que lograron desarrollar y controlar un sistema original que restringía el acceso al oficio regimental a aquellos candidatos de los linajes integrantes de la élite de poder. Este método supuso el inicio del cierre del regimiento talaverano a los miembros del común y el acaparamiento de dichos cargos por parte de la nobleza de la villa. Finalmente, estudiaremos las injerencias externas a este modelo por parte del arzobispo de Toledo, señor de Talavera de la Reina quien, en ocasiones, imponía sus intereses sobre los candidatos propuestos por la villa. No se trata de una división cronológica, ya que el proceso de cierre del cabildo municipal y su control por parte de la nobleza talavera fue un proceso que se inició mientras la élite pechera también ocupaba cargos concejiles, aunque no pudieron mantenerse en el poder, y paralelamente a la intromisión del prelado toledano en las cuestiones de gobierno de la villa, ya que estas incursiones tuvieron lugar durante todo el período bajomedieval, aunque con mayor intensidad desde mediados del Cuatrocientos.

\section{LA INSTITUCIÓN REGIMENTAL EN TALAVERA DE LA REINA: MECANISMOS DE ACCESO, CONTROL Y PERPETUACIÓN EN EL CARGO}

La instauración del regimiento en el concejo de Talavera debió producirse en la segunda mitad del siglo XIV, pero la carencia de documentación nos impide precisar la fecha concreta de la constitución del mismo. El primer documento original en el que se alude a los "Doce caballeros, escuderos y hombres buenos" que gobernaban el concejo talaverano data de $1398^{5}$, aunque existe un traslado no autorizado de una carta de merced de la reina doña María, esposa de Alfonso XI, fechada en 1344 en la que también se hace referencia a esos "doce caballeros". Si bien la autoridad y potestad del escribano para dar fe de la autenticidad del documento copiado debería ser suficiente para aceptar este traslado como primera muestra de la existencia de un cabildo cerrado en Talavera de la Reina, el hecho de que otros documentos coetáneos a este no hagan alusión alguna a estos caballeros regidores, nos lleva a pensar que la mención a los mismos se deba a la introducción deliberada de esta referencia por parte del amanuense, quien ya conocía la existencia de la institución regimental. Esta hipótesis queda reforzada si tenemos en cuenta que en la donación de la villa efectuada por Enrique II al arzobispo Gómez Manrique no se regula la elección de los regidores, pero sí la de otros oficiales concejiles, como los alcaldes y escribanos. Por

\footnotetext{
5 Archivo Histórico Nacional (en adelante AHN), Clero secular-regular, carpeta 2978, documento 14.

${ }^{6}$ AHN, Clero secular-regular, legajo 7118.
} 
lo tanto, parece que la introducción del concejo cerrado en Talavera de la Reina, debió producirse después de la inclusión de la villa bajo el señorío del prelado toledano.

Para conocer el funcionamiento interno del concejo debemos esperar hasta mediados del siglo XV, puesto que las actas municipales talaveranas más antiguas comienzan en septiembre de 1450. Es por ello que en la primera mitad del Cuatrocientos únicamente conocemos los nombres de algunos regidores, enumerados en diversos documentos concernientes al concejo talaverano, pero no tenemos constancia ni del sistema de elección de estos oficiales ni de la duración de los mismos. Es posible que desde sus inicios el cargo de regidor fuera vitalicio, puesto que la reiteración durante varios años consecutivos de los nombres de los integrantes del regimiento, así como el hecho de que a mediados del XV ya contasen con esta característica, nos lleva a plantear esta hipótesis.

\section{LA PARTICIPACIÓN DE LAÉLITE PECHERA EN EL GOBIERNO URBANO}

En la primera mitad del siglo $\mathrm{XV}$, el regimiento estaba compuesto no sólo por la baja nobleza local, sino también por algunos «hombres buenos» pertenecientes a la élite del común que habían obtenido el cargo en estas primeras décadas del siglo XV, cuando el acceso al regimiento todavía no estaba completamente controlado por el grupo nobiliario. Siguiendo el modelo propuesto por Del Val Valdivieso para el obispado de Burgos, aplicable al caso talaverano, durante los primeros años del Cuatrocientos, especialmente en torno a los años veinte, nos encontramos en un período de "afianzamiento definitivo" de los regimientos, momento en el que la clase dominante se enfrenta principalmente a dos cuestiones: quién accede a los puestos de gobierno, y cómo enfrentarse a las luchas concejo-común o, mejor dicho, élite del común 7 .

Para resolver la primera de las dos cuestiones, como analizaremos, se estableció un sistema de acceso al regimiento entre los miembros de los linajes más poderosos de la villa por el cual, tras el fallecimiento de un miembro del gobierno concejil, ocupaba su puesto un integrante de otra familia de la élite de poder, estableciéndose una suerte de lista de espera compuesta por aspirantes que pertenecían al grupo dominante. En cuanto a la cuestión de la oposición concejo-común, al igual que ocurrió en otros concejos castellanos bajomedievales, el proceso de aristocratización y monopolización de los cargos concejiles por el segmento nobiliario tuvo como principal consecuencia la paulatina expulsión del común de los puestos de gobierno.

Si durante la primera mitad del siglo XV encontramos los nombres de algunos integrantes de la élite del común, como Pedro Ruiz, Martín González de Pedraza o los bachilleres Antón González y Alonso Méndez, a los que en ningún documento se les reconoce su condición de hidalguía o su pertenencia al grupo de caballeros y nobles de la villa, desde mediados de este siglo, su número había quedado reducido considerablemente. A diferencia del grupo nobiliario, ni estos oficiales ni sus familiares lograron posicionarse en situación de competir por una regiduría vacante con otros linajes de la villa que sí pertenecían al grupo de caballeros e hidalgos locales. Por lo tanto, estos regidores fueron los únicos miembros de sus respectivos grupos

7 VAL VALDIVIESO, "Transformaciones sociales", p 121. 
familiares que ostentaron el cargo y, tras su fallecimiento, su oficio fue ocupado por un integrante de otro linaje talaverano, generalmente de condición nobiliaria.

\section{EL PROCESO DE ACAPARAMIENTO DE LOS OFICIOS REGIMEN- TALES POR LA NOBLEZA TALAVERANA. LOS MECANISMOS DE CONTROL DE ACCESO AL CARGO}

La situación fue diferente en lo relativo a los regidores integrantes del estrato nobiliario. Durante la primera mitad del siglo XV se documentan los nombres de miembros de poderosos linajes de la villa, que lograron perpetuarse en los cargos generación tras generación, creándose así verdaderas sagas familiares de regidores durante la segunda mitad del Cuatrocientos y el tránsito a la Modernidad. Por ejemplo, en el cabildo que regía Talavera de la Reina en la década de 1430, junto a los oficiales citados anteriormente, encontramos, entre otros, a Diego López de Ayala, tercer señor de Cebolla, hijo de Fernán Álvarez de Toledo, señor de Oropesa; o a los caballeros Lope González de Montenegro o Alvar García de Carvajal. Todos ellos, representantes de familias nobiliarias talaveranas, situaron a sus descendientes en una buena posición en la carrera por el acceso a la regiduría, y lograron, sirviéndose de los mecanismos de gestión interna y control de los cargos de gobierno que analizaremos, que lograsen su ingreso en el cabildo municipal.

Durante la segunda mitad del siglo XV y el tránsito a la Modernidad, es frecuente encontrar apellidos de linajes nobiliarios que operaban en el marco político local desde la primera mitad del Cuatrocientos, no sólo los ya mencionados López de Ayala, Montenegro y García de Carvajal, sino también otras familias como los Duque de Estrada, Loaísa o Meneses. Este hecho, también documentado en decenas de concejos castellanos bajomedievales, carecería de la mayor relevancia si no se analizan las estrategias y mecanismos de los que se sirvieron para perpetuarse en los cargos, controlar el acceso al oficio regimental e integrarse plenamente en la política local de Talavera de la Reina en este período.

La fragmentación de datos hasta la aparición de los Libros de Actas en 1450 impide conocer los mecanismos originales empleados para el acceso de nuevos aspirantes a las regidurías talaveranas. El único requisito indispensable para poder acceder al cargo era poseer la condición de vecino de la villa. Esta obligación estaba relacionada con la primera cláusula del acuerdo firmado entre el arzobispo Gómez Manrique y el concejo de Talavera de la Reina tras la donación de la villa al prelado toledano, en el que se disponía que "los alcaldes, jurados y escribanos que han de ser puestos en la villa sean vecinos de Talavera". Aunque no se hace referencia explícita a los regidores ya que, como hemos señalado, la instauración del regimiento fue posterior a la inclusión de la villa bajo el señorío de la mesa arzobispal toledana, es factible que los oficiales talaveranos se acogieran a esta concordia a la hora de elegir al nuevo aspirante. No importaba que la vecindad se hubiera adquirido sólo unos meses antes, con el probable y casi único propósito de acceder a los oficios municipales. Así lo muestra el caso del regidor Juan de Ponte, sobrino del también regidor Francisco

\footnotetext{
${ }^{8}$ Biblioteca Nacional, Ms. 13084, fols. 45-58.
} 
Ortiz Calderón. Ponte, que fue recibido como vecino, por intercesión de su tío, en noviembre de $1450^{9}$, fue elegido unos meses más tarde, en marzo de 1451, como uno de los dos candidatos presentados por el concejo al arzobispo de Toledo para ocupar la regiduría vacante ${ }^{10}$.

El sistema utilizado para la elección de nuevos oficiales era un procedimiento transaccional, en el que los regidores votaban según una modalidad de doble voto, del que salían dos candidatos que eran presentados al arzobispo de Toledo, siendo el señor de la villa el que designaba y confirmaba al nuevo regidor entre ambos pretendientes ${ }^{11}$. Como veremos, esta fórmula escondía un complejo entramado de intereses linajísticos y de relaciones entre las familias que ostentaban cargos regimentales. Votar a uno u otro de los candidatos suponía alinearse y posicionarse a favor de uno de los linajes de la villa.

Como hemos indicado, y al igual que en la mayoría de concejos castellanos, el oficio de regidor en Talavera de la Reina era vitalicio, al menos desde mediados del siglos XV. A pesar de ello, y a diferencia de otras ciudades, los regidores talaveranos no lograron patrimonializar el cargo; es decir, durante el período bajomedieval, con la salvedad de Pedro Suárez de Toledo, quien renunció a su cargo a favor de su yerno, Juan de Ribera, no se ha documentado la sucesión de padres a hijos en el oficio regimental en Talavera de la Reina, como sí se ha constatado en estudios sobre otros concejos castellanos, como Burgos o Cuenca, donde este tipo de sucesión no planteaba, generalmente, mayores problemas y era aceptado por el resto del regimiento ${ }^{12}$. ¿Por qué los regidores talaveranos no lograron patrimonializar el cargo? Probablemente, su condición de lugar de señorío del arzobispo de Toledo condicionó el campo de actuación de los oficiales talaveranos, ya que en otros lugares bajo dominio del prelado toledano, como Villanueva del Arzobispo, las cuatro regidurías existentes tampoco se patrimonializaron, sino que eran elegidos anualmente entre las familias hidalgas de la villa ${ }^{13}$. Parece que la actuación de los señores de la villa, especialmente desde Alfonso Carrillo, quien da inicio a una política de mayor intervencionismo en el gobierno concejil, así como la carencia de un grupo regimental fuerte que lograse imponer sus intereses sobre los de los eclesiásticos, impidió que en Talavera de la Reina se generalizase la transmisión de los oficios regimentales, ya que otros cargos, como las escribanías, sí fueron objeto de cesión entre padres e hijos, aunque siempre contando con la ratificación y beneplácito del arzobispo de Toledo.

Como anunciábamos, la excepción fue el caso de Pedro Suárez de Toledo, señor de Gálvez y Jumela, vecino y regidor de Talavera hasta 1485. Según la documentación, dicho año renunció en su yerno, Juan de Ribera, señor de Montemayor, su oficio de regiduría, transmisión que fue aceptada en diciembre de ese mismo año por el car-

9 Archivo Municipal de Talavera (en adelante AMT), Libros de Actas (en adelante LLAA) 1450-1459, fol. $33 \mathrm{r}$.

10 AMT, LLAA 1450-1459, fols. 53r-53v.

11 SuÁrez Álvarez, La villa de Talavera, pp. 200-201.

12 Guerrero Navarrete, “«Ser» y «pertenecer» a la élite”, p. 86. Jara Fuente, Concejo, poder y élites, p. 109.

13 García Guzmán, El señorío de Cazorla, pp. 101-103. Como indica la autora, parece que durante la sede vacante entre los arzobispos Sancho de Rojas y Juan Martínez (1422-1424), el canónigo Martín Hernández eliminó dos regidurías y las dos restantes las hizo vitalicias. Pero esta iniciativa tuvo una corta trayectoria ya que en 1423, tras las constantes quejas del concejo, se volvió al sistema tradicional. 
denal González de Mendoza ${ }^{14}$. Este caso debe entenderse como un ejemplo aislado de transmisión patrimonial del oficio regimental, especialmente en la segunda mitad del Cuatrocientos, ya que hasta los primeros años del siglo XVI no se documenta otra posible cesión del cargo. Según los registros municipales, en 1514, al morir Diego López de Ayala, señor de Cebolla, su hijo, Juan de Ayala, presentó una carta de provisión del cardenal Cisneros, quien le hacía merced del oficio de regimiento vacante en Talavera de la Reina. La carencia de la documentación concerniente a dicho hecho nos impide conocer si se trató verdaderamente de una trasmisión del cargo o respondía más bien a una merced que le otorgó el prelado y que coincidió con el fallecimiento de su padre. En nuestra opinión, es más factible que se tratase de una renuncia, como hizo años antes Pedro Suárez de Toledo, y que Jiménez de Cisneros, dada la relevancia que tuvo en el ámbito político-militar el capitán Diego López de Ayala, en un gesto de simpatía y gratitud a la familia, proveyese del cargo al nuevo señor de Cebolla.

Si mantenemos que en ambos casos se trató de una transmisión patrimonial del cargo, debemos plantear la hipótesis de que el consentimiento por el regimiento y por el señor de la villa a ambas cesiones estuvo relacionado con el estatus de nobleza titulada que disfrutaban ambas familias, ya que los Suárez de Toledo y los Ayala, ambos descendientes de Fernán Álvarez de Toledo, segundo señor de Oropesa, eran las únicas familias de Talavera de la Reina que poseían dominios señoriales, Gálvez y Cebolla, respectivamente. Además, debemos tener en cuenta que los progenitores de Pedro Suárez de Toledo y Diego López de Ayala también ostentaron cargos de relevancia en el aparato político talaverano. García Álvarez de Toledo, tercer señor de Oropesa, fue alcalde mayor de Talavera en 1442, año en el que también se documenta la primera aparición de Pedro Suárez de Toledo en la documentación municipa $1^{15}$. Parece que la estrategia familiar desarrollada por los Álvarez de Toledo estuvo orientada a que el segundogénito, Pedro Suárez, mantuviera la posición del linaje como élite dominante en el concejo de Talavera de la Reina, mientras que el primogénito, Fernán Álvarez de Toledo, primer conde de Oropesa, se mantuvo alejado de la política talaverana y centró sus intereses y actuaciones en mantener y acrecentar sus dominios señoriales. Tras el fallecimiento de Pedro Suárez de Toledo, los intereses familiares en la villa fueron defendidos, en un primer momento, por su primogénita, doña Juana de Herrera, esposa del ya nombrado Juan de Ribera; pero fue finalmente su tercera hija, doña Elvira de Toledo, casada con el regidor Diego de Carvajal, y sus descendientes los que ocuparon un lugar preeminente en la política talaverana, especialmente tras 1508. Este año moría Juan de Ribera y desde ese momento el único nexo entre su familia y Talavera de la Reina fueron las posesiones del linaje en la villa, ya que sus descendientes giraron sus intereses políticos hacia Toledo.

Por su parte, tanto Diego López de Ayala como su hijo Juan de Ayala, tercer y cuarto señor de Cebolla, fueron regidores de Talavera. El primero de ellos estuvo presente en el regimiento talaverano, al menos, desde 1435, año en el que don Juan de Cerezuela, arzobispo de Toledo, tomaba posesión de la villa ${ }^{16}$. Juan de Ayala coin-

\footnotetext{
${ }^{14}$ Sección Nobleza del Archivo Histórico Nacional (en adelante SNAHN), Frías, C. 1764, D. 26.

15 AHN, Clero secular-regular, carpeta 2979, documento 17; y AHN, Clero secular-regular, legajo 7118.

${ }^{16}$ Archivo de la Catedral de Toledo, carpeta Z.3.C.1.3.
} 
cidió en el regimiento con su hijo, Diego López de Ayala, situación única en el período estudiado ya que, si bien es frecuente encontrar a dos hermanos ostentando simultáneamente dos regidurías, este es el único caso en el que padre e hijo coinciden como miembros del cabildo. Para entender este particularismo debemos contextualizar el ascenso de Diego López de Ayala, quien primero fue nombrado corregidor de Talavera, al ganar la villa para el bando isabelino en 1478 en el marco la guerra civil castellana ${ }^{17}, \mathrm{y}$ más tarde fue regidor hasta su muerte en 1514.

A tenor de los datos, y dado que los dos únicos ejemplos de transmisión patrimonial se produjeron en el seno de linajes titulados, es factible pensar que dicha cesión tuvo relación con la posesión de señoríos, y que el resto de familias regimentales tuvieron que ceñirse al sistema de reparto de los oficios que, como veremos, fue más rígido y restrictivo en el acceso a la regiduría.

Aparte de estas dos familias que, como hemos analizado, participaron activamente en la vida política talaverana durante gran parte del período bajomedieval, la documentación conservada permite reconstruir verdaderas genealogías de familias en el regimiento talaverano. Meneses, Carvajal, Montenegro, Loaísa, Girón o Duque de Estrada son apellidos de hidalgos y caballeros locales que encontramos asociados al cargo de regidor durante el siglo XV y primeras décadas del siglo XVI. Si, como hemos indicado, no se traspasaba el oficio de padres a hijos, ¿qué mecanismo se empleó por parte de la baja nobleza talaverana para acaparar los oficios regimentales?

Parece que en la Talavera bajomedieval se configuró un sistema de reparto de poder entre linajes regimentales en el que, cuando un regidor fallecía, pasaba a ocupar su lugar un miembro de otra familia integrante de la élite local. Según nuestra hipótesis, el pariente del oficial fallecido, generalmente el hijo, no accedía automáticamente a la regiduría vacante, sino que quedaba a la espera de que llegase el momento en el que fuera el candidato mejor posicionado, con los requisitos y apoyos necesarios para su elección. Hasta entonces, eran miembros de otras familias gobernantes los que accedían a las regidurías que iban quedando vacantes. Aunque son pocos los datos conservados para este período, el examen de la información de la que disponemos nos lleva a pensar que este fue el mecanismo empleado por el concejo talaverano para la distribución de los oficios regimentales, lo que no implicó que no existieran casos en los que no se respetase este proceso, no sólo por los dos casos de transmisión del oficio que hemos analizado, sino también, como tendremos ocasión de comprobar, por la injerencia arzobispal y la provisión de oficios por parte del señor de la villa.

Este sistema de elección resulta original ya que, como es sabido, generalmente, los gobiernos concejiles bajomedievales castellanos siguieron unas pautas comunes que orientaban el proceso hacia la patrimonialización de los oficios regimentales, aunque no todos los lugares siguieron un mismo ritmo ni unos mecanismos similares. Por ejemplo, en Burgos, Guerrero Navarrete ha analizado el mecanismo de acceso a las regidurías, comprobando la existencia de una especie de "protocolo de ascenso",

${ }^{17}$ La derrota de las tropas del arzobispo Carrillo a manos del capitán Diego López de Ayala, contienda en la que también participaron otros vecinos talaveranos como Fernán Duque o Rodrigo de la Rúa, le valió su nombramiento como corregidor de la villa en 1480. Franco SiLva, "El proceso de señorialización de las tierras de Talavera de la Reina", p. 233. Rodríguez-Picavea Matilla, Orígenes y desarrollo de la señorialización, p. 158. 
cuyo culmen era el ingreso en dicha corporación. La aceptación del aspirante al oficio no encontraba ningún obstáculo cuando se producía la transmisión de padres a hijos. Salvo excepciones, el resto de solicitudes eran rechazadas ${ }^{18}$. Por su parte, los regidores madrileños desarrollaron rápidamente los mecanismos de patrimonialización de los oficios y, a pesar de que Juan II intentase ralentizar este proceso, ordenando en 1435 que le propusieran una terna para elegir al nuevo regidor ${ }^{19}$, en el reinado de Enrique IV obtuvieron el privilegio de poder renunciar a su oficio sin necesidad de obtener una licencia regia ${ }^{20}$. Los reinados de Juan II y Enrique IV también fueron escenario de la consolidación de la patrimonialización de las veinticuatrías sevillanas. A través de mecanismos como las cartas de expectativa, la concesión de los oficios por juro de heredad o las licencias para renunciar a los cargos, la mayoría de los integrantes del regimiento lograron patrimonializar el oficio ${ }^{21}$. Finalmente, cabe destacar el caso de Lorca, estudiado por Jiménez Alcázar, que cuenta con cierto grado de similitud con el descrito para Talavera. Según el autor, en el nuevo modelo regimental planteado desde 1490 se estableció un sistema de votación a través del cual el resto de oficiales elegía a una persona apta y hábil para desempeñar el cargo, si bien estos ejemplos fueron escasos, ya que las renuncias de padres a hijos fueron muy habituales en el concejo lorquino en el tránsito a la Modernidad ${ }^{22}$.

La parquedad documental de los fondos municipales talaveranos nos impide conocer con mayor precisión el funcionamiento interno del proceso descrito en referencia al acceso al regimiento. No conocemos en qué momento un miembro del linaje del oficial fallecido era considerado por el resto de regidores como uno de los candidatos que reunían las condiciones necesarias para ser presentado ante el arzobispo; es decir, no sabemos cuántas vacantes debían sucederse para que el miembro de un linaje tuviera opciones para aspirar al oficio. Es probable que este tiempo de espera variase de un caso a otro. Hay que tener en cuenta que las relaciones entre las familias de la élite dominante podían variar dependiendo de la coyuntura o de factores externos al propio ejercicio de gobierno. Un cambio en la articulación de la administración concejil podía provocar un desequilibrio de poder entre los linajes regimentales que podía afectar al mejor posicionamiento de una u otra candidatura, llegando, incluso, a saltar a una generación del linaje que, o no llegaron a recabar los apoyos necesarios para su nombramiento o dirigieron deliberadamente sus intereses hacia otros ámbitos sociopolíticos. Tales son los casos de Diego Duque, hijo del regidor Juan Duque y padre del también regidor Fernán Duque de Estrada, quien no llegó nunca a acceder a un cargo regimental, probablemente por la pérdida de importancia de esta familia en el entramado político talaverano.

${ }^{18}$ Guerrero Navarrete, “«Ser» y «pertenecer» a la élite”, pp. 79-92. Como indica la autora, en el concejo burgalés, durante la segunda mitad del siglo XV y primeros años del Quinientos, se constituyó un proceso de "renuncia en dos etapas": una primera, de asociación al cargo mientras el titular todavía ejercía el oficio, y la renuncia definitiva. De esta manera, Burgos se presenta como un ejemplo paradigmático de automatización y protocolización del proceso de renuncia del oficio de regimiento.

19 Castellanos Oñate, "El regimiento madrileño”, pp. 443-445.

${ }^{20}$ Losa Constreras, El concejo de Madrid, pp. 286-288.

21 Navarro Sainz, El concejo de Sevilla, pp. 155-156.

22 JimÉnez AlCÁzAr, Un concejo de Castilla en la frontera de Granada, pp. 332-339. 
Según este sistema, la votación realizada por el resto de los regidores, se configuró como un elemento clave, donde quedaban patentes los apoyos y las relaciones entre linajes. Generalmente, en esta votación los regidores que participaban hacían un reparto equilibrado de los votos entre los dos aspirantes mejor posicionados.

Cuadro 1. Votación para la elección del oficio de regiduría vacante. 1451

\begin{tabular}{|l|l|l|}
\hline Oficial & Primer voto & Segundo voto \\
\hline Lope Carrillo, corregidor & Juan de Ponte & García Jufre de Loaysa \\
\hline Alonso Méndez, bachiller, regidor & Juan de Ponte & García de Loaysa \\
\hline Lope González de Montenegro, regidor & García Jufre de Loaysa & Juan de Vega \\
\hline Pedro de Cerezuela, regidor & Juan de Ponte & García de Jufre \\
\hline Álvaro de Loaysa, regidor & García Jufre & Juan de Vega \\
\hline Fernando de Talavera, regidor & Juan de Ponte & Gonzalo Palomeque \\
\hline Francisco Ortiz Calderón, regidor & Juan de Ponte & Gonzalo Palomeque \\
\hline Fernando de Barrionuevo, regidor & García Jufre de Loaysa & Juan de Vega \\
\hline Juan de Arévalo, regidor & Juan de Ponte & García Jufre de Loaysa \\
\hline Fernando García Caballero, procurador & Juan de Ponte & García Jufre de Loaysa \\
\hline
\end{tabular}

Como muestra el cuadro 1, en la elección de 1451, celebrada para cubrir la vacante por la muerte del bachiller Juan Rodríguez, en la que intervinieron ocho regidores, el corregidor y el procurador, la mayoría de ellos eligieron como primera opción a Juan de Ponte, quedando Garcí Jufre de Loaísa como su candidato preferente en su segundo voto. De entre ellos, fue finalmente Juan de Ponte el que obtuvo la carta de designación y confirmación del arzobispo de Toledo que le permitía el acceso a la regiduría ${ }^{23}$.

Este procedimiento se configuró, en primer lugar, como un mecanismo de control de acceso a las regidurías por parte de la élite dominante a través del cual los dirigentes talaveranos confeccionaron un marco de legalidad para dar salida a las aspiraciones de algunos de los miembros de las familias más poderosas de la villa. Pero, además, este método de elección permitía conocer la situación de cada linaje con respecto al conjunto del grupo gobernante, así como los vínculos existentes entre estos linajes, los apoyos recibidos para el desarrollo de sus estrategias y las relaciones establecidas con otros agentes sociales talaveranos, como aquellos miembros de la élite del común cuyos nombres salían reflejados en las votaciones.

La carencia de pleitos y quejas ante el Consejo Real o cualquier otra instancia de poder supraconcejil, nos lleva a pensar que este sistema no generó enfrentamientos entre los diferentes grupos de poder más allá de las rivalidades tradicionales entre

23 AMT, LLAA 1450-1459, fols. 53r-53v. El licenciado Garcí Jufre de Loaísa no logró acceder al puesto de regidor pero, tal como muestran los registros municipales, se mantuvo en la órbita de poder del regimiento, realizando numerosas mandas y servicios por orden del concejo. 
los linajes. En ocasiones, esta enemistad alcanzaba un grado de violencia muy elevado, cuya máxima expresión fue el asesinato del licenciado Garcí Jufre de Loaísa, miembro de una de las familias que ostentaron frecuentemente cargos políticos en el concejo, a manos de tres criados del regidor Fernán Álvarez de Meneses ${ }^{24}$. A pesar de este terrible suceso, no se debe entender que en Talavera existieran bandos-linajes enfrentados entre sí como se han documentado en concejos del cantábrico o en ciudades del centro peninsular, como Toledo ${ }^{25}$.

Como hemos indicado, este método de elección también nos permite observar las relaciones dentro del grupo dirigente y de éstos con miembros de la élite del común. Volviendo a la votación de 1451, recogida en el cuadro 1, se pueden observar tres líneas de actuación llevadas a cabo por los regidores en la elección. En primer lugar, encontramos una posición de neutralidad, seguida por el corregidor, el bachiller Alonso Méndez, Pedro de Cerezuela, Juan de Arévalo y el procurador, Fernando García Caballero. Estos electores optaron por emitir un voto favorable para los dos principales candidatos aunque en todos los casos su primera opción fue Juan de Ponte. En segundo lugar, se observa la estrategia desarrollada por el grupo favorable a Garcí Jufre de Loaísa, encarnado por su familiar, Álvaro de Loaísa, Lope González de Montenegro y Fernando de Varrionuevo. En esta ocasión, los regidores votaron como su primera opción al aspirante Loaísa, escogiendo alternativa para su segundo voto a Juan de Vega, probablemente con el objetivo de restar votos a Ponte, sin duda el rival más fuerte de Loaísa por su filiación con el regidor Francisco Ortiz. Finalmente, los partidarios de Juan de Ponte, Fernando de Talavera y Francisco Ortiz, optaron por una estrategia similar a la anterior, con la diferencia de emitir su voto a favor de Gonzalo Palomeque, miembro de otro linaje de la élite del común.

El sistema parece que se mantuvo en los primeros años del siglo XVI. En 1510 fue elegido Bernardino de Meneses como regidor, tras el fallecimiento del contador Diego de Talavera ${ }^{26}$; aunque, como tendremos ocasión de comprobar, la injerencia del cardenal Jiménez de Cisneros, señor de la villa, fue decisiva en los nombramientos de regidores en la primera década del Quinientos.

La relación de fuerzas entre los diferentes linajes que componían el regimiento no sólo quedó patente en la votación de 1451. Como sucedía en numerosos concejos castellanos, una de las facultades de los regidores talaveranos era la elección de oficiales menores del regimiento, tales como procuradores, fieles de la plaza, escribanos o mayordomos. Las votaciones para el nombramiento de estos cargos que se recogen en los acuerdos municipales muestran la relación de fuerzas, así como los apoyos e intereses de cada uno de los linajes de la villa, que en ocasiones chocaban con los de otros miembros del regimiento. Por ejemplo, en julio de 1509, el cabildo se reunió para la elección de un escribano para ocupar la vacante de Antón Bermudo, quien había fallecido sin renunciar al cargo en otra persona. En la votación que se realizó, se aprecia la división del regimiento en dos facciones, encabezadas por los Meneses y los Ayala. Al no llegar a un acuerdo en la sesión del 11 de julio, se volvieron a reunir

${ }^{24}$ Archivo General de Simancas, Registro General del Sello, Leg. 149901, 56.

${ }^{25}$ Díaz de DuRana y Fernández de LarRea, "Las villas cantábricas bajo el yugo de la nobleza”, pp. 55-64. LóPez Gómez, La sociedad amenazada, p. 177-178.

${ }^{26}$ AMT, LLAA 1510-1511, fol. 22v. 
dos días más tarde y, probablemente tras negociar en privado sobre el asunto, llegaron a una concordia por la que fue elegido Bartolomé de Arévalo, candidato defendido por los Meneses ${ }^{27}$.

\section{INJERENCIAS EXTERIORES Y RUPTURA DEL PROCESO DE ELECCIÓN}

Como hemos indicado, este proceso no siempre fue respetado por los prelados toledanos. En varias ocasiones, como en los casos de Ruy García de la Rúa, García de Villarroel o Baltasar Corral, en 1456, 1501 y 1508 respectivamente, los arzobispos hicieron valer su condición de señores de la villa para designar como regidores a sus criados y clientes, concibiendo en estos casos el oficio como una forma de gratificación, como una merced por los servicios prestados ${ }^{28}$. Aunque en los dos primeros casos el nombramiento del nuevo regidor por parte del arzobispo suscitó las quejas y protestas del concejo, que pedía que se respetasen los usos y costumbres de la villa en esta materia, la voluntad de los prelados prevaleció y los regidores tuvieron que aceptarlos en el cargo.

Estas protestas fueron especialmente intensas en el primero de los ejemplos. En febrero de 1456, Ruy García de la Rúa, escribano, presentó la carta del arzobispo Alfonso Carrillo en la que le proveía de la regiduría vacante por la muerte de Francisco Ortiz Calderón ${ }^{29}$. Esta concesión fue realizada como gratificación por los servicios prestados por el escribano a la familia Carrillo de Acuña ${ }^{30}$. El nombramiento de García de la Rúa debe contextualizarse en un momento, mediados del Cuatrocientos, en el que la injerencia señorial en la vida política talaverana se había limitado, casi en exclusiva, a la confirmación de privilegios y ordenanzas concejiles, y a la resolución de pleitos relativos a los bienes concejiles y el derecho de los vecinos a su uso. Por este motivo, el concejo se mostró reticente a su cumplimiento y, si bien aceptó la misiva como carta de su señor, antes de admitirlo en el oficio regimental, envió a Toledo a los regidores Fernando de Talavera y Álvaro de Loaísa para que, tras reunirse con el regidor Pedro Suárez de Toledo, quien ya se encontraba en la ciudad, tratasen con el prelado la cuestión de la merced concedida al escribano, que suponía una violación de sus derechos tradicionales de elección de cargos concejiles ${ }^{31}$. Finalmente, tras unas negociaciones favorables a los intereses de Carrillo, a tenor de los resultados, Ruy García de la Rúa fue finalmente recibido como regidor el 21 de abril de $1456^{32}$.

27 AMT, LLAA 1508-1509, fols. 126r y $127 \mathrm{r}$.

28 AMT, LLAA 1450-1459, fols. 174r y 175v; AMT, LLAA 1500-1501, fols. 69r-70r; AMT, LLAA 1508, fols. $51 \mathrm{v}-52 \mathrm{r}$.

29 Parece que la familia García de la Rúa pertenecía al estrato hidalgo de la villa, como así lo demuestra su capacidad para nombrar apaniaguados en las monedas que debían pagar los pecheros de la villa, privilegio que sólo disfrutaban en Talavera de la Reina los caballeros e hidalgos. AMT, LLAA 1450-1459, fols. 17v, 21r, $46 \mathrm{r}, 195 \mathrm{r}, 235 \mathrm{v}, 241 \mathrm{v}$.

30 Para conocer más sobre la familia García de la Rúa, consúltese nuestro trabajo “«E por muchas obras e ayudas que de vos he resçibido»".

31 AMT, LLAA 1450-1459, fol. 174r.

32 AMT, LLAA 1450-1459, fol. 178r. 
Aunque Ruy García pertenecía a una de las familias de la élite de participación de la villa, puesto que tanto él como sus hermanos habían ostentado cargos en la órbita del regimiento, su integración en la vida política talaverana estuvo marcada, en los primeros años, por el malestar, todavía latente, del resto de oficiales, quienes observaron con recelo cualquier actuación del nuevo regidor ${ }^{33}$.

Si hasta la primera mitad del siglo XV la intervención arzobispal se había limitado a estos asuntos, desde el acceso a la mitra toledana de Alfonso Carrillo, Talavera de la Reina verá la cada vez mayor intrusión señorial en cuestiones políticas y económicas del concejo. El caso de Ruy García de la Rúa suponía, al menos por primera vez documentado, el cortocircuito del proceso de elección de los candidatos a las regidurías vacantes tan celosamente guardado por el resto de miembros del cabildo talaverano.

Parece que Ruy García de la Rúa no fue la única persona que obtuvo la merced del oficio de manos de Alonso Carrillo. En la década de 1470, encontramos a un criado del arzobispo, Francisco de Cienfuegos, como regidor talaverano. La carencia documental nos impide conocer los orígenes de este personaje, ya que hasta su aparición como regidor no hay noticia alguna de la presencia de esta familia en la villa. Si no pertenecía a ningún linaje de la élite dominante, ¿cómo accedió a la regiduría? Es factible suponer que, dada su condición de criado del señor de Talavera, su llegada al regimiento fue concedida por el prelado toledano, aunque también es posible que accediera al oficio por los cauces habituales, ya que Francisco de Cienfuegos estuvo casado con Elvira de la Rúa, hija de Ruy García de la Rúa, quien ya había fortalecido su posición en el entramado sociopolítico talaverano. Si tenemos en cuenta el caso de Juan de Ponte quien, como hemos explicado, fue elegido regidor unos meses después de obtener la condición de vecino de la villa, proceso favorecido por su tío, el regidor Francisco Ortiz Calderón, la opción de la intercesión de Ruy García a favor de su yerno es una hipótesis factible. Dada la falta de información sobre una posible merced es arriesgado aceptar una u otra opción.

En la segunda mitad del Cuatrocientos, se percibe la cada vez mayor intervención de los señores en cuestiones relativas al gobierno local. Durante el pontificado del cardenal González de Mendoza, la actuación del prelado en este aspecto fue más comedida, limitándose a sugerir al cabildo talaverano el candidato que él consideraba más idóneo, elección que seguía los intereses políticos de la Corona. Se han conservado dos cartas, fechadas en 1485 y 1486 en las que se proponía la elección como regidor del doctor Rodrigo Maldonado, miembro del Consejo Real. En la primera de ellas, firmada en mayo de 1485, don Pedro González de Mendoza sugería la elección de Maldonado de Talavera "por ser persona tan principal" para ostentar la regiduría vacante por el fallecimiento de Pedro Suárez de Toledo ${ }^{34}$. En este caso, la propuesta del cardenal no tuvo efecto alguno ya que, como hemos indicado, fue el propio González de Mendoza el que aceptó la renuncia de la regiduría de Pedro Suárez de Toledo a favor de su yerno, Juan de Ribera.

33 Por ejemplo, en 1457, fue necesaria la intervención del arzobispo para que le pagasen el salario que debía haber percibido el año anterior por Navidad, como el resto de oficiales, pero le apercibieron que "de aquí adelante si fuera ausente, que no se lo librarán". AMT, LLAA 1450-1459, fol. 225r.

34 AMT, Gobierno, legajo 5, signatura 1111. 
En la segunda misiva, enviada un año después, el mismo arzobispo recuerda al regimiento que los reyes habían prometido a Rodrigo Maldonado la primera regiduría vacante en Talavera, por lo que les pide que no pusieran "escusa ni dilación" en la elección de Maldonado tras el fallecimiento del regidor Alonso de Montenegro ${ }^{35}$. Aunque no tenemos constancia de que el doctor Maldonado accediese finalmente al cargo, su hijo, el comendador Arias Maldonado, y su nieto, el también comendador Pedro Cervantes, sí lo ejercieron a principios del siglo XVI.

Como puede observarse, el cambio en la política seguida por los señores de la villa con respecto a la provisión de oficios regimentales es evidente. Alfonso Carrillo inició el proceso de intervención en el gobierno de Talavera de la Reina nombrando a dos regidores pertenecientes a su red clientelar, entendiendo, de esta manera, la provisión del oficio como una merced, como una gratificación por los servicios prestados. La cada vez mayor intervención señorial en cuestiones referentes al gobierno y administración de la villa alcanzó, con la llegada del cardenal Francisco Jiménez de Cisneros a la sede toledana, unas cotas que no se habían vivido desde que la villa pasó del realengo al régimen señorial. Jiménez de Cisneros hizo prevalecer su concepción del oficio de regimiento como merced y su capacidad para proveer del mismo a su elección, sin respetar los usos y costumbres de la villa. Si en 1501 únicamente designó a García de Villarroel, su maestresala ${ }^{36}$, en 1508 , fueron dos los candidatos que presentaron la carta de provisión del oficio de regiduría vacante, y fue el propio concejo quien tuvo que optar por uno de los dos aspirantes, Baltasar del Corral, maestresala del cardenal, o Juan de Villarroel, contino de su casa ${ }^{37}$.

El cabildo eligió finalmente a Baltasar del Corral, quien renunció al cargo unos días después. Con su cese, accedió a la regiduría Diego de Meneses, cuyo nombramiento significó el posicionamiento del linaje Meneses como uno de los más poderosos del concejo $^{38}$. La aceptación en la regiduría de Baltasar del Corral parece una estrategia seguida por los miembros del regimiento, en especial por la familia Meneses, para obtener el reintegro del oficio en un integrante de la clase dominante talaverana. La pronta renuncia de Corral y la provisión del oficio a Meneses, todo ello en menos de un mes, parece una maniobra para satisfacer a la élite de poder de Talavera de la Reina, puesto que, aunque el maestresala recibía en primera instancia el cargo, éste revirtió finalmente en un miembro de un linaje regimental, con el beneplácito del resto del cabildo.

Juan de Villarroel hubo de esperar hasta 1511 para acceder al oficio regimental. Tras el fallecimiento del comendador Estrada en abril de ese año, Fernando Cornejo, vecino de Talavera, presentaba ante el concejo una carta del cardenal en la que proveía el oficio a Villarroe ${ }^{39}$. Al igual que en el caso de Ruy García de la Rúa, el regimiento se mostró reticente a aceptar al criado del mayordomo como nuevo regidor de la villa. Iniciaron un proceso de negociaciones con el cardenal y, finalmente,

\footnotetext{
35 AMT, Gobierno, legajo 5, signatura 1111.

36 AMT, LLAA 1500-1501, fols. 69v-70v.

37 AMT, LLAA 1508, fols. 51v-52v, y 55r-55v.

38 AMT, LLAA 1508, fols. 51r-v, y 62v.

39 AMT, LLAA 1510-1511, fols. 99r y 103v-104r. AMT, Gobierno, legajo 5, signatura 1111.
} 
aceptaron a Juan de Villarroel como regidor el 7 de junio de $1511^{40}$. Con este nombramiento, los Villarroel, un importante linaje al servicio del cardenal Cisneros, asentaba su poder en la villa ${ }^{41}$.

\section{CONCLUSIONES}

Como hemos analizado en estas páginas, a lo largo de la segunda mitad del siglo $\mathrm{XV}$, asistimos en Talavera de la Reina a un proceso de cierre y control del acceso al gobierno municipal por parte de la élite dominante. El sistema utilizado para ello se basó, principalmente, en dos líneas de actuación. En primer lugar, gestaron un sistema de elección en el que eran los propios oficiales regimentales quienes proponían dos candidatos al arzobispo de Toledo, señor de la villa, para que fuera éste quien proveyese el oficio a uno de ellos. A través de este sistema, los regidores y las familias a las que pertenecían aseguraban que el elegido para ocupar la regiduría fuera un integrante de la élite de poder.

La ruptura de este sistema, cuyo reflejo principal lo encontramos en la injerencia de los arzobispos toledanos en la provisión del oficio como una merced, produjo una reacción de defensa de los derechos del concejo por el resto de regidores, como queda patente en el ejemplo de Ruy García de la Rúa. Dado que, en ocasiones, los designios de los prelados chocaban con los intereses del cabildo, adoptaron una segunda línea de actuación, basada en una política pactista, en la que negociaban con el señor de la villa la aceptación de sus candidatos a cambio de elegir ellos mismos al sustituto en caso de renuncia de éste, como ocurrió en el caso de Baltasar del Corral.

Este sistema se perfiló como una muestra más del reparto de poder entre los linajes más poderosos de Talavera; pero, a su vez, dejaba entrever qué familias tenían más peso en el entramado sociopolítico del concejo y quiénes contaban con mayores recursos para posicionar a un miembro de su grupo en situación de acceder, en primera instancia, a la votación y, en segundo lugar, al cargo. De esta manera, a través de este juego de reparto de poderes, la nobleza talaverana consiguió hacerse con el control de las regidurías, logrando la expulsión de aquella élite de pecheros que en la primera mitad del Cuatrocientos formaba parte del gobierno municipal.

Durante la segunda mitad de esta centuria, asistimos a un proceso de acaparamiento de oficios por parte de dos linajes, principalmente, los Ayala y los Meneses, que serán los que cuenten con un mayor número de representantes en el cabildo talaverano a comienzos del siglo XVI. En el lado opuesto, encontramos la desaparición de algunos linajes caballerescos del regimiento de Talavera de la Reina, como los Loaysa. En una posición intermedia se sitúan otras familias que se mantuvieron en el oficio regi-

\footnotetext{
40 AMT, LLAA 1510-1511, fols. 122r-122v.

41 A lo largo de la década de 1500, encontramos tres miembros del linaje Villarroel ostentando cargos de importancia en el gobierno talaverano. Como muestran las actas concejiles, entre 1500 y 1502 , Sancho de Villarroel fue designado por el cardenal Cisneros como corregidor de Talavera de la Reina. Como indicamos, García de Villarroel fue aceptado en la regiduría vacante por el fallecimiento de Pedro Suárez de Meneses, pero parece que renunció al oficio entre 1502 y 1507, puesto que este último año se presenta ante el regimiento con una merced del arzobispo por la que es nombrado alguacil de la villa (AMT, LLAA 1510-1511, fols. 27v y $31 v-32 r)$.
} 
mental, sin acrecentar su número, pero sin perder peso en el gobierno concejil, tales como los Carvajal o los Estrada. Pero la dinámica de intromisión del prelado toledano alteró este modelo de gestión de provisión de las regidurías talaveranas y, al inicio del reinado de Carlos I, se documenta la llegada de apellidos nuevos al regimiento, como Zúñiga o Manuel, fruto de las mercedes concedidas como consecuencia del cada vez mayor intervencionismo de los señores de la villa, y que fueron desplazando paulatinamente a aquellos linajes del gobierno concejil que no supieron desarrollar una estrategia adecuada que les permitiera adaptarse a la nueva situación.

\section{BIBLIOGRAFÍA}

Asenjo Gonzélez, María, Segovia: la ciudad y su tierra a fines del Medievo, Segovia: Diputación Provincial de Segovia, 1986.

Asenjo GonzÁlez, Espacio y sociedad en la Soria Medieval, siglos XIII-XV, Soria: Diputación de Soria, 1999.

Asenjo Gonzélez, María, "Las ciudades medievales castellanas. Balance y perspectivas de su desarrollo historiográfico", En la España Medieval, 28 (2005), pp. 415453.

Castellanos Oñate, José Manuel, "El regimiento madrileño (1464-1515)", Anales del Instituto de Estudios Madrileños, 30 (1991), pp. 439-462.

Cerdá Ruiz-Funes, Joaquín, "Hombres buenos, jurados y regidores en los municipios castellanos de la Baja Edad Media" en Actas del I Symposium de Historia de la Administración, Madrid: Instituto de Estudios Administrativos, 1970, pp. 161-206.

Collantes de Terán Sánchez, Antonio, "Las ciudades de Andalucía desde el siglo XIII a comienzos del XV" en Antonio Collantes de Terán, Una gran ciudad. Sevilla, Sevilla, 2008, pp. 225-262.

Díaz de Durana Ortiz de Urbina, José Ramón y Fernández de Larrea, Jon Andoni, "Las villas cantábricas bajo el yugo de la nobleza. Consecuencias sobre los gobiernos urbanos durante le época Trastámara" en José María Monsalvo Antón (ed.), Sociedades urbanas y culturas políticas en la Baja Edad Media castellana, Salamanca: Ediciones Universidad de Salamanca, 2013, pp. 49-70.

Franco SiLVA, Alfonso, "El proceso de señorialización de las tierras de Talavera de la Reina en el siglo XV. El caso de Cebolla y los Ayala", Anuario de Estudios Medievales, 20 (1990), pp. 223-275.

García Guzmán, María del Mar, El señorío de Cazorla en la Baja Edad Media, Cádiz: Ayuntamiento de Cazorla, 2006.

Guerrero NAVARREte, Yolanda, “«Ser» y «pertenecer» a la élite: estrategias de reproducción del poder en el Burgos bajomedieval" en José Antonio Jara Fuente (coord.), Ante su identidad. La ciudad hispánica en la Baja Edad Media, Cuenca: Ediciones de la Universidad de Castilla-La Mancha, 2013, pp. 75-92.

Jara Fuente, José Antonio, Concejo, poder y élites. La clase dominante en Cuenca en el siglo XV, Madrid: Consejo Superior de Investigaciones Científicas, 2000. 
JARA Fuente, José Antonio, "Estructuras formales de poder y de organización de las clases dominantes urbanas en Castilla. El regimiento: una crisis del siglo XIV en el siglo XV", Edad Media. Revista de Historia, 8 (2007), pp. 225-241.

JiMÉNEZ AlCÁZAR, Juan Francisco, Un concejo de Castilla en la frontera de Granada: Lorca 1460-1521, Granada: Universidad de Granada y Ayuntamiento de Lorca, 1997.

LóPez Gómez, Óscar, La sociedad amenazada: crimen, delincuencia y poder en Toledo a fines del siglo XV, Toledo: Ayuntamiento de Toledo, 2007.

Losa Contreras, Carmen, El concejo de Madrid en el tránsito de la Edad Media a la Edad Moderna, Madrid: Dykinson, 1999.

Lozano CAstellanos, Alicia, "«E por muchas obras e ayudas que de vos he resçibido». El linaje García de la Rúa y Talavera de la Reina a mediados del siglo XV: ejemplo de ascenso social y político por servicio al señor de la villa", Historia, Instituciones y Documentos, 41 (2014), pp. 321-344.

Martín Cea, Juan Carlos, y Bonachía Hernando, Juan Antonio, "Oligarquías y poderes concejiles en la Castilla Bajomedieval: balance y perspectivas", Revista d'Història Medieval, 9 (1998), pp. 17-40.

Monsalvo Antón, José María, El sistema político concejil. El ejemplo del señorio medieval de Alba de Tormes y su concejo de villa y tierra, Salamanca: Ediciones de la Universidad de Salamanca, 1988.

Monsalvo Antón, José María, "La sociedad política en los concejos castellanos de la Meseta durante la época del regimiento medieval. La distribución social del poder" en Concejos y ciudades en la Edad Media hispánica. II Congreso de Estudios Medievales, Madrid: Fundación Sánchez Albornoz, 1990, pp. 357-413.

Navarro Sainz, José María, El concejo de Sevilla en el reinado de Isabel I (14741504), Sevilla: Diputación de Sevilla, 2007.

Quintanilla Raso, Concepción, "El dominio de las ciudades por la nobleza. El caso de Córdoba en la segunda mitad del siglo XV", En la España Medieval, 10 (1987), pp. 109-124.

Rodríguez-Picavea Matilla, Orígenes y desarrollo de la señorialización en la villa de Talavera y su tierra (siglos XIII-XV), Talavera de la Reina, Excmo. Ayuntamiento de Talavera de la Reina, 2007.

RucQuoI, Adeline, "Valladolid, del concejo a la Comunidad" en Emilio Sáez, Cristina Segura y Margarita Cantera (coords.), La ciudad Hispánica durante los siglos XIII al XVI. Actas del Coloquio celebrado en La Rábida y Sevilla del 14 al 19 de septiembre de 1981, Madrid: Editorial de la Universidad Complutense, II, pp. 745772.

SuÁrez Álvarez, María Jesús, La villa de Talavera y su tierra en la Edad Media (1369-1504), Oviedo: Universidad de Oviedo y Diputación Provincial de Toledo, 1982. 
Val Valdivieso, María Isabel, "The urban oligarchy's affairs in the government of Castilian towns in the Late Middle Ages" en Marc Boone y Peter Stabel (eds.), Shaping urban identity in Late Medieval Europe, 2000, pp. 255-267.

Val Valdivieso, María Isabel, "Transformaciones sociales y luchas por el poder en el área del obispado de Burgos a fines de la Edad Media", Edad Media: revista de Historia, 3 (2000), pp. 115-152. 